\title{
Multisystemic production of interleukin 10 limits the severity of acute pancreatitis in mice
}

\author{
J-L Van Laethem, R Eskinazi, H Louis, F Rickaert, P Robberecht, J Devière
}

\begin{abstract}
Background-Interleukin 10 (IL-10) decreases the severity of experimental acute pancreatitis. The role of endogenous IL-10 in modulating the course of pancreatitis is currently unknown.

Aims-To examine the systemic release of IL-10 and its messenger RNA production in the pancreas, liver, and lungs and analyse the effects of IL-10 neutralisation in caerulein induced acute pancreatitis in mice.
\end{abstract}

Methods-Acute necrotising pancreatitis was induced by intraperitoneal caerulein. Serum levels of IL-10 and tumour necrosis factor (TNF), and tissue IL-10 and TNF- $\alpha$ gene expression were assessed. After injecting control antibody or after blocking the activity of endogenous IL-10 by a specific monoclonal antibody, the severity of acute pancreatitis was assessed in terms of serum enzyme release, histological changes, and systemic and tissue TNF production.

Results-In control conditions, serum IL-10 levels increased and correlated with the course of pancreatitis, with a maximal value eight hours after induction. Both IL-10 and TNF- $\alpha$ messengers showed a similar course, and were identified in the pancreas, liver, and lungs. Neutralisation of endogenous IL-10 significantly increased the severity of pancreatitis and associated lung injury as well as serum TNF protein levels $(+75 \%)$ and pancreatic, pulmonary, and hepatic TNF messenger expression $(+33 \%,+29 \%$, $+43 \%$, respectively).

Conclusions-In this non-lethal model, systemic release of IL-10 correlates with the course of acute pancreatitis. This antiinflammatory response parallels the release of TNF and both cytokines are produced multisystemically. Endogenous IL-10 controls TNF- $\alpha$ production and plays a protective role in the local and systemic consequences of the disease. (Gut 1998;43:408-413)

Keywords: pancreatitis; interleukin 10; tumour necrosis factor $\alpha$; adult respiratory distress syndrome

Acute necrotising pancreatitis is characterised by inflammatory and necrotic events which follow the initial intra-acinar injury involving enzyme activation and disruption of the acinar cytoskeleton. ${ }^{1}$ The severity of the process may be highly variable, ranging from a limited local involvement of the pancreas to a multisystemic disease similar to septic shock. Although the pathogenesis of inflammation and necrosis in pancreatitis is only partly understood, proinflammatory cytokines, such as interleukin 1 (IL-1), IL-8, and tumour necrosis factor $\alpha$ $(\mathrm{TNF}-\alpha)$ seem to play a major role in this process. ${ }^{2-4}$ Blocking these mediators by specific antagonists has resulted in a dramatic decrease in the severity of pancreatitis. ${ }^{4-6}$

Interleukin 10 is a major anti-inflammatory cytokine, and is able to inhibit the in vitro production of proinflammatory cytokines by activated monophages/macrophages. ${ }^{78}$ In vivo, IL-10 prevents death and controls endogenous production of TNF during endotoxaemia. ${ }^{9}$ Administration of recombinant IL-10 before the induction of pancreatitis prevents necrosis and reduces severity in caerulein induced necrotising pancreatitis in mice. ${ }^{10}$ Even when administered after the induction of acute pancreatitis, IL-10 is also able to attenuate its severity in a rat model. ${ }^{11}$ One of the suggested mechanisms of action is inhibition of the local release of TNF- $\alpha$ by monophages/ macrophages. ${ }^{10-12}$ TNF- $\alpha$ was confirmed to originate from the pancreatic activated inflammatory cells and its expression is dramatically increased during the first few hours after the induction of pancreatitis. ${ }^{12} 13$

Whether IL-10 is endogenously released and plays a role during acute pancreatitis is currently unknown. The purposes of the present study were: (1) to assess the systemic release of IL-10 and its messenger RNA (mRNA) expression in the pancreas, liver, and lungs in the model of acute necrotising pancreatitis in mice; and (2) to analyse the effects of blockade of endogenous IL-10 on the course of pancreatitis in terms of pancreatic enzyme release and histological changes, on systemic, pulmonary, liver, and pancreatic TNF- $\alpha$ production and on the development of pancreatitis associated lung injury.

\section{Materials and methods}

ANIMALS AND REAGENTS

Female NMRI mice (aged 5-6 weeks, weight range $15-25 \mathrm{~g}$ ) were fed with a standard diet and fasted for 24 hours before induction of pancreatitis. They received water ad libitum during the experiments. Caerulein was kindly provided by Pharmacia (Brussels, Belgium). Neutralising mouse IL-10 monoclonal antibody was a rat IgG1 (JES5-2A5) produced in ascites form in mice. Hybridomas were kindly provided by $\mathrm{T} R$ Mossmann (Department of Immunology, University of Alberta, Edmonton, Canada). ${ }^{14}$ Briefly, they were produced from a rat that was immunised with partially
Accepted for publication 4 March 1998 
Table 1 Histological scoring for acute pancreatitis

\begin{tabular}{lll}
\hline Condition & Score & Indication \\
\hline Oedema & 0 & Absent \\
& 1 & Focally increased between lobules \\
& 2 & Diffusely increased between lobules \\
Inflammatory cell infiltrate & 3 & Acini disrupted and separated \\
& 1 & Absent \\
Acinar necrosis & 2 & In ducts (around ductal margins) \\
& 3 & In the parenchyma (in $<50 \%$ of the lobules) \\
& 0 & In the parenchyma (in $>50 \%$ of the lobules) \\
& 1 & Periductal necrosis $(\leqslant 5 \%)^{\star}$ \\
& 2 & Focal necrosis $(5-20 \%)$ \\
& 3 & Diffuse parenchymal necrosis $(20-50 \%)$ \\
\hline
\end{tabular}

^Approximate percentage of cells involved per field examined.

purified proteins from supernatants of induced Th2 cells and enriched for IL-10. ${ }^{14}$ The monoclonal antibody in the supernatant was isolated by a solid phase radioimmunoadsorbent assay using ${ }^{35} \mathrm{~S}$-methionine labelled secreted proteins from a lectin stimulated Th2 clone. Ascites of LO-dinitrophenyl (DNP) hybridoma cells (a kind gift from $\mathrm{H}$ Bazin, Experimental Immunology Unit, Catholic University of Louvain, Belgium), secreting a rat IgG1 monoclonal antibody with antidinitrophenyl specificity (LODNP) was used as control. ${ }^{15}$ The endotoxin levels of these preparations were below $100 \mathrm{pg} / \mathrm{ml}$ as determined by a Limulus amoebocyte lysate assay (Chromogenix, Nodia, La Hulpe, Belgium).

EXPERIMENTAL PROCEDURE

Acute pancreatitis was induced by four intraperitoneal injections of caerulein $(50 \mu \mathrm{g} / \mathrm{kg})$ at hourly intervals as previously described. ${ }^{16}$ Blood samples were obtained by retro-orbital puncture under ether anaesthesia at different time points after induction of pancreatitis. The animals were then killed by neck dislocation and the pancreas, liver, spleen, and lungs were removed in toto and cut into two. One part was fixed in Bouin's solution for 12 hours and embedded in paraffin wax for histological analysis; the other part was immediately frozen in liquid nitrogen and stored at $-80^{\circ} \mathrm{C}$ until RNA extraction.

Neutralisation of endogenous IL-10 was achieved by a $4 \mathrm{mg}$ intraperitoneal anti-IL-10 monoclonal antibody injection two hours before the first administration of caerulein. This monoclonal antibody was shown to be specific for IL-10. As previously reported, it blocks the biological activity of IL-10 in vitro ${ }^{14}$ and is able to prevent the effects of exogenous IL-10 in mice. ${ }^{9}$ The dose used and the time of administration were based on previous in vivo experiments: a dose of $4 \mathrm{mg}$ anti-IL-10 monoclonal antibody increased TNF- $\alpha$ levels significantly in murine models of endotoxaemia and hepatotoxicity, comparative to control monoclonal antibody pretreatment, and abolished the detection of circulating IL-10 in these conditions. ${ }^{17} 18$

ASSAYS

Serum amylase and lipase were measured at $30^{\circ} \mathrm{C}$ by automated chromogenic and turbidimetric assays, respectively, according to the manufacturer's recommendations (Boehringer Mannheim, Brussels, Belgium). Results are expressed in international units (IU). The upper normal limits are $4500 \mathrm{IU}$ for amylase and $300 \mathrm{IU}$ for lipase.

Serum levels of TNF- $\alpha$ and IL-10 were determined using commercially available enzyme linked immunosorbent assay (ELISA) kits (Factor-test-X and Interest-10-X, Genzyme, Cambridge, Massachusetts). Sensibility was 20 and $16 \mathrm{pg} / \mathrm{ml}$ for TNF- $\alpha$ and IL-10, respectively.

\section{HISTOLOGICAL GRADING FOR ACUTE} PANCREATITIS

Pancreatic sections $(6 \mu \mathrm{m})$ were stained with haematoxylin and eosin and graded in a blinded manner. The extent and severity of oedema, inflammatory cell infiltrate, and acinar necrosis were graded from $0-3$ (table 1 ), by two independent investigators, as previously described. ${ }^{10}$ Liver and lung sections were similarly stained with haematoxylin and eosin and assessed for histological changes.

POLYMERASE CHAIN REACTION ANALYSIS OF IL-10 AND TNF- $\alpha$ GENE EXPRESSION

Total cellular RNA was extracted from the pancreas, liver, and lung using the commercially available RNA isolation reagent RNA NOW (Biogentex, Seabrook, Texas) and was quantitated by ultraviolet absorbance at 260 $\mathrm{mm}$. A $1 \mu \mathrm{g}$ aliquot of total RNA was reverse transcripted into complementary DNA using Moloney murine leukaemia virus reverse transcriptase (GIBCO BRL, Gent, Belgium) as previously described..$^{10}$ Polymerase chain reaction (PCR) was performed on $2 \mu \mathrm{l}$ of the resulting complementary DNA using a PerkinElmer/Cetus thermocycler (Norwalk, Connecticut) for 30 cycles (denaturation, one minute at $93^{\circ} \mathrm{C}$; annealing, one minute at $55^{\circ} \mathrm{C}$ for IL-10 and $60^{\circ}$ for TNF- $\alpha$ and $\beta$-actin; extension, one minute at $72^{\circ} \mathrm{C}$ ). The sequence of the primers used were: sense, 5'TCTCATCAGTTCTATGGCCC-3', 5'-ATG CAGGACTTTAAGGGTTACTTG-3'; and antisense, 5'-GGGAGTAGACAAGGTACAA C-3'， 5'-CTAGACACCTTGGTCTTGGAG CTTA-3' for TNF- $\alpha$ and IL-10, respectively. They were selected to span an intronic sequence to differentiate mRNA from contaminating DNA in tissue RNA preparations. The predicted size of the amplified cDNA fragment was 212 base pairs for TNF- $\alpha$ and 254 base pairs for IL-10. Amplification of $\beta$ actin gene was similarly performed on the same samples to assess RNA amount and integrity.

Complementary DNA control for the expression of TNF- $\alpha$ and IL-10 mRNA was similarly prepared from total RNA extracted from NMRI mouse liver or spleen treated with $100 \mu \mathrm{g}$ lipopolysaccharide (Sigma Chemical Co., St Louis, Missouri) one hour before sacrifice.

The PCR products were run on $2 \%$ agarose gels, stained by ethidium bromide, and then photographed and assessed. A semiquantitative measurement of the relative TNF- $\alpha$ mRNA levels in pancreas, liver, and lungs was achieved using a computer assisted densitometric scanning (Bio 1d, Vilber Lourmat Biotechnology, 


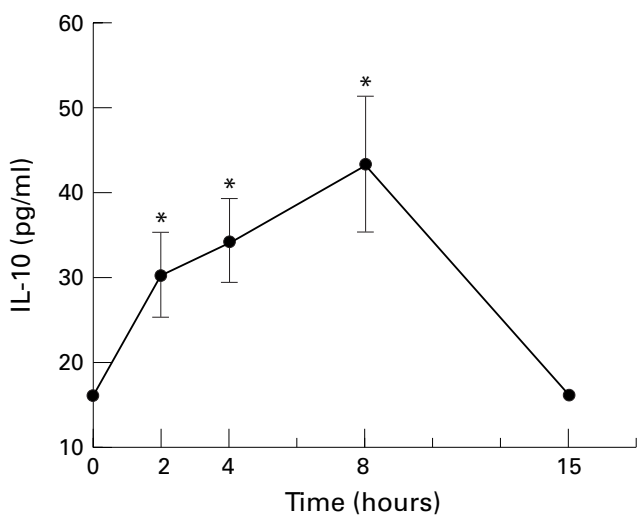

Figure 1 Time course of serum IL-10 levels after induction of pancreatitis (time 0 corresponds to the first caerulein injection). Values are expressed as mean (SD) for each time point: $n=8$ ( 2 hours); $n=12$ ( 4 hours); $n=13$ ( 8 hours); $n=15$ ( 15 hours). ${ }^{*} p=0.03$ ( 2 hours), $p=0.012$ ( 4 hours), $p=0.008$ ( 8 hours), compared with time 0.

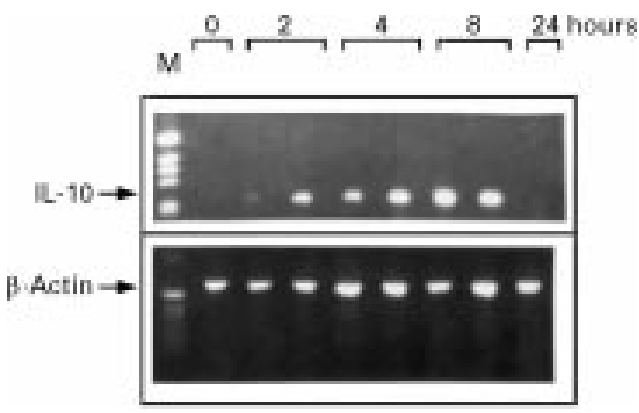

Figure 2 Kinetics of the representative expression of $I L-10$ $m R N A$ in the pancreas during acute pancreatitis (three mice tested at each time point). $M$, molecular weight marker.

Marne-la-Vallée, France) after optimisation of the PCR experiments, ensuring that the PCR was performed during the exponential phase of DNA synthesis. Three mice were used for each time point, the PCR experiments being performed twice.

STATISTICAL ANALYSIS

Results are expressed as mean (SD). Comparisons between groups were assessed using the Mann-Whitney U test. A p value less than 0.05 was considered statistically significant.

\section{Results}

IL-10 PRODUCTION DURING ACUTE PANCREATITIS Systemic $I L-10$ release

IL-10 serum levels were not detectable before the induction of pancreatitis (time 0). They showed an increase two hours after the start of caerulein injections and were significantly increased from two to eight hours after induction with a peak mean value of 43.8 (17) $\mathrm{pg} / \mathrm{ml}$ (fig 1). At 15 hours, no systemic IL-10 was detected.

\section{IL-10 and TNF- $a$ mRA expression in pancreas,} liver, and lungs

No constitutive expression of IL-10 and TNF- $\alpha$ mRNA was found in normal tissues. Tissue mRNA expression of both cytokines disclosed a similar course, beginning to increase two hours after induction of pancreatitis and reaching a maximal intensity eight hours after the initiation of acute pancreatitis (fig 2). This was observed not only in the pancreas but also in the liver (fig 3A) and lungs where both TNF- $\alpha$ and IL-10 mRNAs were strongly and similarly expressed at eight hours (fig 3B). Messenger RNA expression returned to basal values 24 hours after the induction of pancreatitis.

The course of IL-10 serum and mRNA expression paralleled that of pancreatic enzyme levels and histological pancreatic alterations with highest levels and a maximal mRNA intensity detected eight hours after induction.

During acute pancreatitis, in addition to pancreatic lesions, histological examination of the lungs disclosed oedema and inflammatory cell infiltrate (mainly neutrophils) within the alveolar architecture, with a maximal intensity at eight hours. In contrast, no significant histological alteration was seen in the liver (not shown).

EFFECTS OF BLOCKADE OF IL-10 ON THE COURSE OF PANCREATITIS

None of the animals died during the experiments.
B

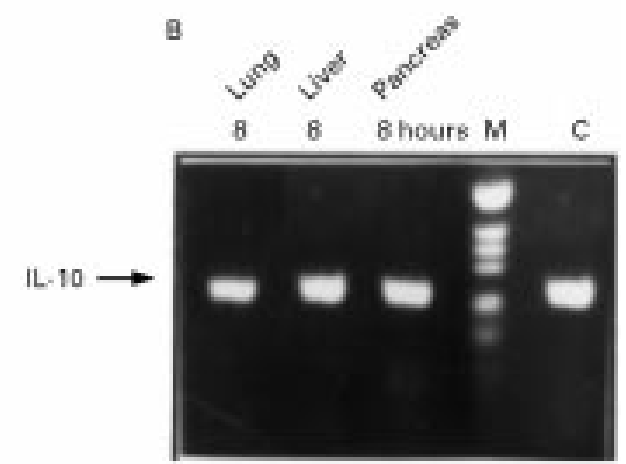

Figure 3 (A) Representative expression of TNF-a mRNA in the liver during the course of acute pancreatitis. Two positive controls (+LPS) were included showing high expression of TNF- $\mathrm{mRNA}$ in the liver one hour after intraperitoneal injection of $100 \mu \mathrm{g}$ lipopolysaccharide. (B) Expression of IL-10 $m R N A$ in the pancreas, liver, and lungs at the time of maximal pancreatitic intensity. M, molecular weight marker. $C$, positive control from the liver $(+L P S)$. 

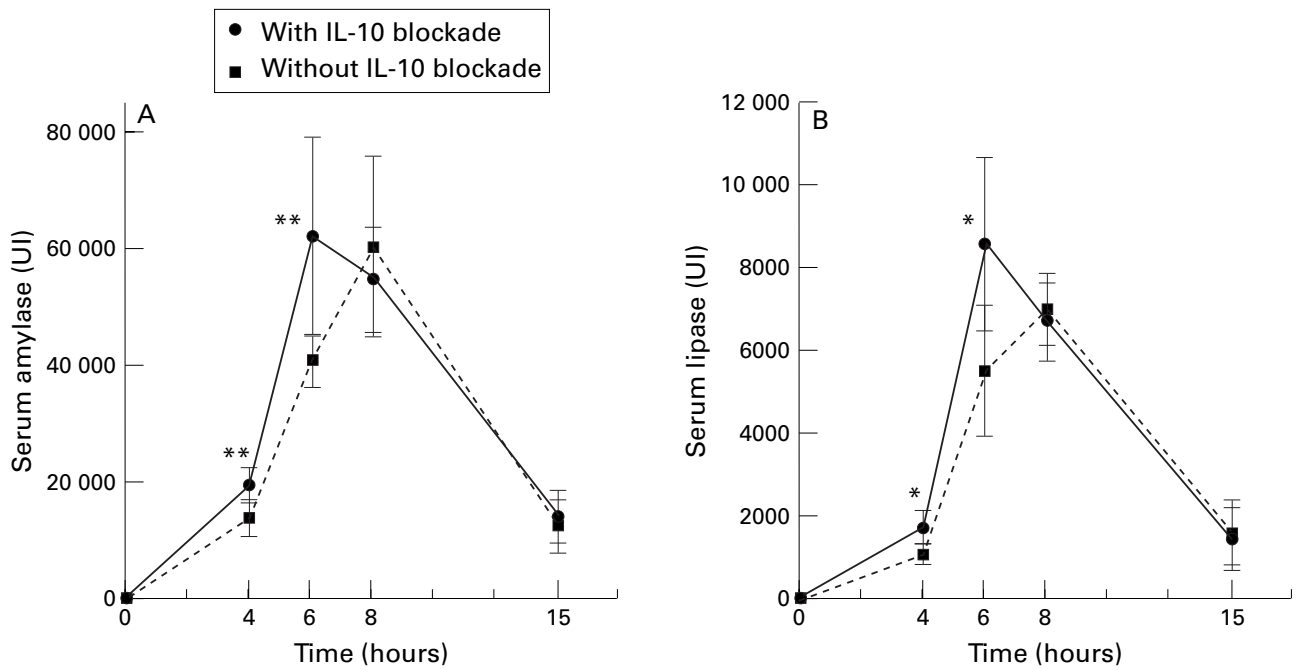

Figures 4 Kinetics of serum amylase $(A)$ and lipase (B) levels after induction of pancreatitis. Values are mean (SD); $n=10$ at each time point. ${ }^{\star} p<0.05,{ }^{\star}{ }^{\star} p<0.01$.

Serum amylase and lipase levels

Figure 4 shows the kinetics of serum amylase and lipase levels after injecting control (LODNP) or anti-IL-10 monoclonal antibodies and inducing pancreatitis. IL-10 neutralisation resulted in a significantly faster increase in both amylase and lipase levels compared with the control group. The differences were statistically significant at four and six hours after the induction of pancreatitis, disclosing an earlier peak of enzyme release (six hours compared with eight hours in controls, after the start of caerulein administration) in anti-IL-10 monoclonal antibody treated animals $(p=0.01$ and $\mathrm{p}=0.001$ for amylase, and $\mathrm{p}=0.03$ and $\mathrm{p}=0.04$ for lipase, four and six hours after the first caerulein injection, respectively). At eight and 15 hours, amylase and lipase levels decreased and no significant difference was observed between the groups.

Histological changes in the pancreas

Histological alterations were more severe in animals pretreated with anti-IL-10 monoclonal

Table 2 Histological changes in caerulein induced pancreatitis with or without IL-10 blockade

\begin{tabular}{lll}
\hline $\begin{array}{l}\text { Time after starting caerulein } \\
\text { injection }\end{array}$ & $\begin{array}{l}\text { Acute pancreatitis }+ \text { IL-10 } \\
\text { monoclonal antibody }\end{array}$ & $\begin{array}{l}\text { Acute pancreatitis }+ \text { control } \\
\text { monoclonal antibody }\end{array}$ \\
\hline 4 hours $(\mathrm{n}=10)$ & $1.6(0.5)$ & \\
Oedema & $2.2(0.4)^{\star}$ & $1.4(0.5)$ \\
Inflammation & $2.3(0.5)^{\star}$ & $1.6(0.5)^{\star}$ \\
Necrosis & $6.1(0.5)^{\star}$ & $4.8(0.8)^{\star}$ \\
Global score & & \\
6 hours (n = 8) & $2.5(0.7)^{\star}$ & $1.8(0.6)^{\star}$ \\
Oedema & $2.8(0.4)^{\star}$ & $2.0(0.4)^{\star}$ \\
Inflammation & $2.9(0.4)^{\star}$ & $2.1(0.6)^{\star}$ \\
Necrosis & $8.1 \pm 1.1)^{\star \star}$ & $5.9(1.1)^{\star \star}$ \\
Global score & & \\
8 hours (n = 8) & $2.0(0)$ & $1.6(0.5)$ \\
Oedema & $2.4(0.4)^{\star \star}$ & $1.6(0.5)^{\star \star}$ \\
Inflammation & $1.8(0.4)$ & $2.0(0.4)$ \\
Necrosis & $6.2(0.8)$ & $5.2(1.0)$ \\
Global score & $1.3(0.2)$ & $1.1(0.5)$ \\
15 hours (n=10) & $1.8(0.4)$ & $1.4(0.4)$ \\
Oedema & $0.8(0.4)$ & $0.6(0.2)$ \\
Inflammation & $3.9(1.0)$ & $3.1(1.1)$ \\
Necrosis &
\end{tabular}

Each animal was graded histologically once and then a mean (SD) score was calculated for each parameter in each group. The global score is the combined blind histological score of the three parameters.

${ }^{\star} \mathrm{p}<0.05 ;{ }^{\star \star} \mathrm{p}<0.01$ antibody (table 2), especially regarding inflammatory cell infiltrate and necrosis, while oedema was not significantly different between the two groups. They paralleled amylase and lipase serum levels, showing earlier and increased severity in the case of IL-10 neutralisation. The differences were significant at four and six hours but persisted at eight hours with respect to the extent of inflammatory cell infiltrate; histological scores (table 1) gradually decreased at 15 hours in both groups.

Systemic and pancreatic TNF-a production No detectable IL-10 was observed in the serum of mice pretreated with anti-IL-10 monoclonal antibody. Serum levels of TNF- $\alpha$ were measured four and eight hours after the first caerulein injection in mice pretreated with anti-IL-10 monoclonal antibody or with control monoclonal antibody. In the control group, TNF- $\alpha$ serum levels slightly increased four hours after induction of pancreatitis and returned to undetectable levels after eight hours (fig 5). In mice treated with anti-IL-10 antibodies, a significant increase in TNF- $\alpha$ levels was observed at four hours $(+44 \%$, $\mathrm{p}<0.05)$, persisting at eight hours $(+75 \%$, $\mathrm{p}<0.01$ ) (fig 5), indicating that endogenously produced IL-10 controls TNF- $\alpha$ release in this model.

Pancreatic TNF- $\alpha$ mRNA levels were measured six hours after the induction of acute pancreatitis (fig 6) and were similarly overexpressed in the group pretreated with anti-IL-10 monoclonal antibody compared with controls (relative value: $+33 \%$; $n=5$ in each group; $\mathrm{p}<0.05)$.

\section{Hepatic and pulmonary TNF- $a$ expression and} lung injury

As observed in the pancreas, TNF- $\alpha$ mRNA levels assessed at six hours were significantly higher in the liver (+43\%) and in the lungs $(+29 \%)$ in animals treated with anti-IL-10 monoclonal antibody compared with controls $(n=5$ in each group; $\mathrm{p}<0.05)$.

No histological liver injury was evident in either group. In contrast, increased interstitial 


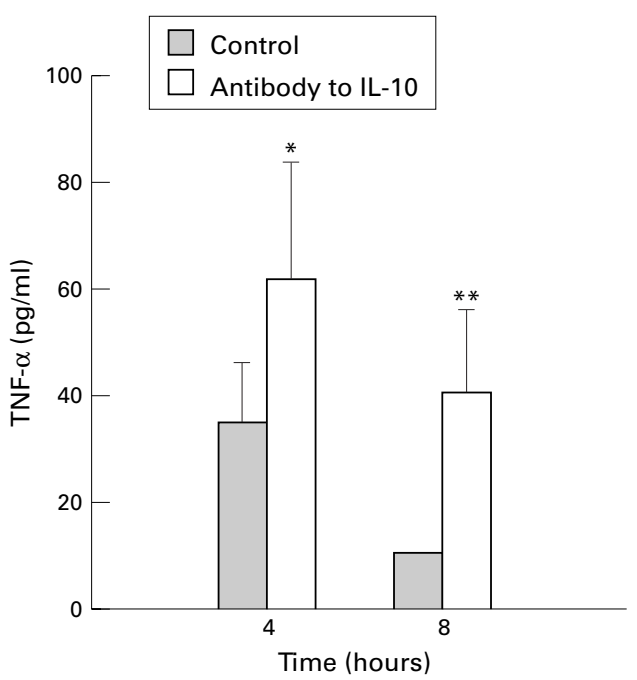

Figure 5 Serum TNF-a levels after pretreatment with anti-IL-10 monoclonal antibody or control monoclonal antibody, four and eight hours after induction of pancreatitis. Values expressed as mean (SD); $n=8$ in each group; threshold value of detection was $20 \mathrm{pg} / \mathrm{ml} .{ }^{\star} p<0.05,{ }^{\star \star}{ }_{p}<0.01$.

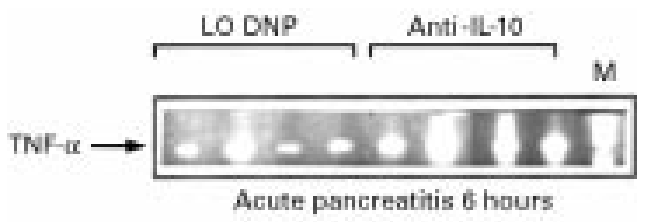

Figure 6 Assessment of TNF- $a m R N A$ during acute pancreatitis. $M$, molecular weight marker.

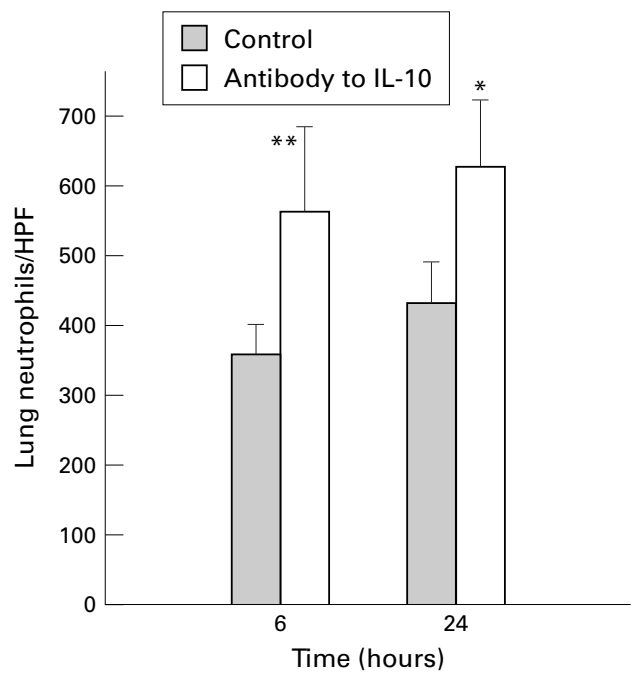

Figure 7 Neutrophil count in the lungs of mice pretreated with anti-IL-10 monoclonal antibody and controls. Results expressed as mean (SD)/high power field (HPF); the numbers of neutrophils were counted in $10 \mathrm{HPF}$ from five lungs in each group. ${ }^{\star \star} p<0.001,{ }^{\star} p<0.008$.

oedema formation, intra-alveolar haemorrhage, and neutrophil sequestration were observed in the lungs of mice pretreated with anti-IL-10 compared with controls. As an objective marker, the lung neutrophil count per high power field (light microscopy $\times 400$ ) was significantly higher at six hours $(\mathrm{p}<0.001)$ and 24 hours $(p<0.008)$ when endogenous IL-10 was blocked before the induction of pancreatitis (fig 7).

\section{Discussion}

The present study reports that in this model of acute necrotising pancreatitis, and in the absence of major multiorgan complications and death, systemic IL-10 secretion is observed which correlates with the course of the pancreatitis. This anti-inflammatory response parallels the release of proinflammatory cytokines. Despite the limited extent of the lesions, the secretion of both pro- and antiinflammatory cytokines is multisystemic. We also show that endogenous IL-10 controls pancreatic, liver, and lung TNF- $\alpha$ production and plays a protective role in the development of pancreatic inflammation and necrosis in this setting. It also attenuates the pancreatitis associated lung injury.

Cytokines play a major role in the development of inflammation and necrosis during experimental and human acute pancreatitis. Experimentally, blocking the proinflammatory cytokine cascade, even after the initiation of pancreatitis, results in a dramatic decrease in the severity as well as the lethality of the phenomena. ${ }^{10-12} 19{ }^{20} \mathrm{IL}-1$ and TNF- $\alpha$ have been shown to be implicated in the promotion of inflammation and acinar necrosis in different models of acute pancreatitis. ${ }^{46}$ Their principal sources are the inflammatory cells, mainly monophages/macrophages, infiltrating the pancreas after the initial intra-acinar injury, which results in zymogen activation and release. ${ }^{1}$ Blocking proinflammatory cytokine release by pretreatment with IL-10 does not alter the early phase of pancreatitis but dramatically reduces its severity at the time of maximal necrosis (eighth hour). ${ }^{10}$ Exogenous IL-10 probably acts, in part, through the inhibition of local TNF- $\alpha$ production by activated monophages/macrophages. These results were recently confirmed by two studies that pointed out the key role played by proinflammatory cytokines after the initiation of pancreatic injury. Indeed, both IL-10 and IL-1 receptor antagonist were able to attenuate the progress of the disease even when administered after the induction of pancreatitis. ${ }^{511}$

Although the present model of caerulein induced pancreatitis is moderately severe and never associated with mortality or multiple organ failure, ${ }^{21}$ systemic release of IL-10 is observed, which parallels the rise of TNF- $\alpha$ in serum and in the pancreatic parenchyma during the progress of pancreatitis. The inflammatory cells infiltrating the pancreatic parenchyma are probably the local source of IL-10 detected in the pancreas, as observed for TNF- $\alpha .{ }^{13}$ However, despite the limited extent of this experimental disease, strong expression of both IL-10 and TNF- $\alpha$ mRNAs was identified not only in the pancreatic tissue but also in the liver and the lungs. These data support the fact that, even in moderately severe pancreatitis, multisystemic production of pro- and anti-inflammatory cytokines is observed in response to local injury. The liver is the major source of IL-10 in many clinical and experimental conditions including orthotopic liver transplantation, septic shock, extracorporeal circulation, or experimental hepatitis or peritonitis. ${ }^{22-26}$ We observed, in this toxic non-lethal model of pancreatitis, that the 
liver is also a major producer of proinflammatory and anti-inflammatory cytokines, despite the lack of any significant histological lesions. Pulmonary alterations may be also found during caerulein induced pancreatitis, consisting of interstitial oedema, increased vascular permeability, and infiltration of neutrophils and macrophages which are the presumed producers of cytokines in the lungs. ${ }^{27}$

Another major finding of this study is the increased severity of pancreatitis after blockade of endogenous IL-10. Interestingly, not only were histological alterations more severe, they were also observed, together with serum enzymes, at an earlier peak after induction of pancreatitis, indicating that endogenous IL-10 plays a strategic and early role in regulating and limiting events promoting inflammation and necrosis. Endogenous IL-10 may exert its beneficial effects by different mechanisms. It potentially down regulates the expression of ICAM-1 and VCAM-1, ${ }^{28-31}$ inhibits the adhesion of leucocytes to activated endothelial cells, and controls the release of IL- 1 , which is also involved in neutrophil adhesion, and of IL-8, a potent chemoattractant for neutrophils. ${ }^{32}$ TNF- $\alpha$ is known to be a major mediator in the development of pancreatitis and also participates in neutrophil recruitment and adhesion molecule up regulation. As supported directly by the present results, endogenous IL-10 controls, at least in part, the production of local and systemic TNF- $\alpha$, as its neutralisation leads to an increase in pancreatic, hepatic, and pulmonary $\mathrm{TNF}-\alpha$ mRNA expression as well as TNF- $\alpha$ serum levels. Endogenous IL-10 also appears to play a role in the attenuation of lung neutrophil sequestration and subsequent injury. This suggests that the overwhelming of regulatory events involving IL-10 may also participate in the development of multiple organ failure in more severe pancreatitis.

In summary, IL-10 has a multisystemic production even during the course of this moderately severe disease. Endogenously produced IL-10 acts not only by controlling the local inflammatory response but also has a key role in regulating promotion of the multisystemic reaction, notably pancreatitis associated lung injury. The progress, extent, and severity of the disease probably depend on the relative imbalance of the inflammatory and antiinflammatory responses. Whether this imbalance is further regulated during the course of pancreatitis remains to be elucidated. The pharmacological modulation of these two responses-that is, superinduction of IL-10 and inhibition of $\mathrm{TNF}$ - may thus potentially influence the course of acute pancreatitis and its pulmonary complications and could play a role in the design of new clinical strategies.

J-L Van Laethem, R Eskinazi, and H Louis were supported by grants from the Fondation Erasme. The authors wish to acknowledge E Quertinmont, C Duponchelle, and F MartinezVadillo for helpful technical assistance.

1 Jungermann J, Lerch MM, Weidenbach H, et al. Dissassembly of rat pancreatic acinar cell cytoskeleton during supramaximal secretagogue stimulation. Am 7 Physiol 1995;G328-38.

2 Heath DL, Cruickshank DH, Gudgeon M, et al. Role of interleukin- 6 in mediating the acute phase protein response and potential as an early means of severity assessment in acute pancreatitis. Pancreas 1993;66:41-5.

3 Viedma JA, Perez-Mateo M, Dominguez JE, et al. Role of nterleukin-6 in acute pancreatitis. Comparison with C-reactive protein and phospholipase A. Gut 1992;33: $1264-7$

4 Grewal HP, Mohey EDA, Gaber L, et al. Amelioration of the physiologic and biochemical changes of acute pancreatitis using an anti-TNF alpha polyclonal antibody. Am f Surg 1994;167:214-19.

5 Norman J, Franz M, Messina J, et al. Interleukin-1 receptor antagonist decreases severity of experimental acute pancreatitis. Surgery 1994;117:648-55.

6 Norman J, Franz M, Fink G, et al. Decreased mortality of severe acute pancreatitis after proximal cytokine blockade. Ann Surg 1995;221:625-34.

7 Bogdan C, Vodovotz Y, Nathan C. Macrophage deactivation by interleukin-10. f Exp Med 1991;174:1549-55.

8 de Waal MR, Abrams J, Bennett B, et al. Interleukin-10 (IL10) inhibits cytokine synthesis by human monocytes: an 10) inhibits cytokine synthesis by human monocytes: an autoregulatory role of IL-10

9 Gerard C, Bruyns C, Marchant A, et al. Interleukin-10 reduces the release of tumor necrosis factor and prevents lethality in experimental endotoxemia. F Exp Med 1993; 177:547-50.

10 Van Laethem JL, Marchant A, Delvaux A, et al. Interleukin-10 prevents necrosis in murine experimental pancreatitis. Gastroenterology 1995;108:1917-22.

11 Rongione AJ, Kusske AM, Kwan K, et al. Interleukin-10 reduces the severity of acute pancreatitis in rats. Gastroenterology 1997;112:960-7.

12 Norman J, Fink G, Franz $M$, et al. Active interleukin-1 receptor required for maximal progression of acute pancreatitis. Ann Surg 1996;223:163-9.

13 Norman J, Fink G, Fray MS. Acute pancreatitis induces intrapancreatic tumor necrosis factor gene expression. Arch Surg 1995;130:966-70.

14 Mosmann TR, Schumacher JH, Fiorentino DF, et al. Isolation of monoclonal antibodies specific for IL-4, IL-5, IL-6, and a new $\mathrm{Th}_{2}$ specific cytokine (IL-10) synthesis inhibitor factor by using a solid phase radioimmunoadsorbent assay. fImmunol 1990;145:2938-45.

15 Platteau B, Rits M, Cormant F, et al. Production and characterization of rat-rat hybridomas against DNP-Hamyten. ies. Boca Raton, Florida: CRC Press, 1990:281-5.

16 Niederau C, Ferrell L, Grendell JH. Cerulein-induced acute necrotizing pancreatitis in mice: protective effects of proglumide, benzotript and secretin. Gastroenterology 1985;88: 1192-204.

17 Marchant A, Bruyns C, Vandenabeele $\mathrm{P}$, et al. Interleukin-10 controls interferon $\gamma$ and tumor necrosis factor production during experimental endotoxemia. Eur $\mathcal{F}$ factor production during exper

18 Louis H, Le Moine O, Peny MO, et al. Production and role of interleukin-10 in concavalin A-induced hepatitis in mice. Hepatology 1997;25:1382-9.

19 Kusske AM, Rongione AJ, Ashley SW, et al. Interleukin-10 prevents death in lethal necrotizing pancreatitis in mice. Surgery 1996;120:284-9.

20 Norman J, Fink G, Messina J, et al. Timing of tumor necrosis factor antagonism is critical in determining outcome in murine lethal acute pancreatitis. Surgery 1996;120:515-21.

21 Gorelick FS, Adler G, Kern HF. Cerulein-induced pancreatitis. In: Go VLW, Di Magno EP, Gardner JD, et al, eds. The pancreas, biology, pathobiology and disease. 2nd edn. New pancreas, biology, pathobiology and

22 Le Moine O, Marchant A, Durand F, et al. Systemic release of interleukin-10 during orthotopic liver transplantation. Hepatology 1994;20:889-92.

23 Marchant A, Alegre ML, Hakim A, et al. Clinical and biological significance of interleukin-10 plasma levels in patients with septic shock. F Clin Immunol 1995;15:265-72.

24 Wan S, Marchant A, Desmet JM, et al. Human cytokine response to cardiac transplantation and coronary artery bypass grafting. F Thorac Cardiovasc Surg 1996;111:469-77. Endogenous IL-10 protects mice from death during septic peritonitis. F Immunol 1995;155:5397-401.

26 Louis H, Le Moine O, Peny MO, et al. Hepatoprotective role of interleukin-10 in galactosamine/lipopolysaccharide
mouse liver injury. Gastroenterology 1997;112:935-42.

27 Guice KS, Adham KT, Caty MG, et al. Neutrophildependent, oxygen-radical mediated lung injury associated dependent, oxygen-radical mediated lung injury assoc

28 Jaeschke H, Farhood A, Smith CW. Neutrophil-induced liver cell injury in endotoxin shock is a CD11b/CD18dependent mechanism. Am f Physiol 1991;261:G1051-6.

29 Entman ML, Yanker K, Shoji T, et al. Neutrophil-induced oxidative injury of cardiac myocytes: a compartmented system requiring CD11b/CD18 ICAM-1 adherence. $\mathcal{f}$ Clin Invest 1992;89:602-9.

30 Krakaver T. IL-10 inhibits the adhesion of leukocytic cells to IL-1 activated endothelials cells. Immunol Lett 1995;45:61-5.

31 Willems F, Marchant A, Delville JP, et al. Interleukin-10 inhibits B7 and intercellular adhesion molecular-1 expres-
sion on human monocytes. Eur f Immunol 1994;24:1007-9. Cion mocytes. Eur f Immunol 1994;24:1007-9. 10) inhibits the release of proinflammatory cytokines from human polymorphonuclear leukocytes. Evidence for an human polymorphonuclear leukocytes. Evidence for an ating the production of IL-8 triggered by lipopolysacating the production of IL-8 trigge
chride. $\mathcal{F} \operatorname{Exp}$ Med 1993;178:2207-11. 